\title{
HPV Analysis in Distinguishing Second Primary Tumors from Lung Metastases in Patients with Head and Neck Squamous Cell Carcinoma
}

\author{
Justin A. Bishop ${ }^{1}$, Takenori Ogawa ${ }^{2}$, Xiaofei Chang ${ }^{2}$, Peter B. Illei ${ }^{1}$, Edward Gabrielson ${ }^{1,3}$, \\ Sara I. Pai ${ }^{2,3}$, and William H. Westra ${ }^{1,2,3}$ \\ ${ }^{1}$ Department of Pathology, The Johns Hopkins Medical Institutions, Baltimore, Maryland, U.S.A. \\ 2Department of Otolaryngology-Head and Neck Surgery, The Johns Hopkins Medical Institutions, \\ Baltimore, Maryland, U.S.A. \\ ${ }^{3}$ Department of Oncology, The Johns Hopkins Medical Institutions, Baltimore, Maryland, U.S.A.
}

\section{Abstract}

For patients with head and neck squamous cell carcinoma (HNSqCC), the development of squamous cell carcinoma (SqCC) in the lung may signal a new primary or the onset of metastatic dissemination. Although the distinction influences prognosis and therapy, it may not be straightforward on histological or clinical grounds. Human papillomavirus (HPV) is an etiologic agent for SqCCs arising from the oropharynx, but not for SqCCs arising from other head and neck sites. For patients with HNSqCC who develop a lung SqCC, HPV analysis could be useful in establishing tumor relationships. High risk HPV in-situ hybridization was performed on 54 lung SqCCs from patients with a prior $\mathrm{HNSqCC}$, and on 166 primary lung carcinomas from patients without prior HNSqCC. HPV was detected in 11 of 220 (5\%) cases. All HPV-positive cases were from patients with a prior oropharyngeal SqCC. For the paired oropharyngeal and lung SqCCs, HPV status was concordant in $95 \%$ of cases. Time from treatment of the HPV-positive oropharyngeal carcinomas to detection of the lung carcinoma ranged from 1 to 97 months (mean 36 months). Two HPV-positive cancers were detected in the lung 8 years after treatment of the oropharyngeal primary. Despite the long interval, E6 sequencing analysis of one of these paired samples confirmed that the tumors harbored the same HPV-16 variant. HPV does not appear to play a role in the development of primary lung cancer. For patients with oropharyngeal SqCC who develop lung SqCCs, HPV analysis may be helpful in clarifying tumor relationships. These relationships may not be obvious on clinical grounds as HPV-related HNSqCC may metastasize long after treatment of the primary tumor.

\section{Keywords}

Human papillomavirus; lung carcinoma; oropharyngeal squamous cell carcinoma

\footnotetext{
Address correspondence/reprint requests to: William H. Westra, M.D., The Weinberg Building, room 2242, The Johns Hopkins Hospital, 401 North Broadway, Baltimore, MD 21231-2410, Phone: 410/955-2163, Fax: 410/955-0115,wwestra@jhmi.edu.

This is a PDF file of an unedited manuscript that has been accepted for publication. As a service to our customers we are providing this early version of the manuscript. The manuscript will undergo copyediting, typesetting, and review of the resulting proof before it is published in its final citable form. Please note that during the production process errors may be discovered which could affect the content, and all legal disclaimers that apply to the journal pertain.
} 


\section{Introduction}

Patients with $\mathrm{HNSqCC}$ are at risk of developing second primary tumors and distant metastases, and the lung is a common site for both.(22,27,37) The distinction between a second primary tumor and metastasis is critical: a second primary lung carcinoma may be low stage and resectable, whereas a metastasis is an ominous finding that heralds the onset of widespread tumor dissemination with no options for curative intervention. Although the distinction is important, it is often difficult. Pathologic evaluation is advocated for patients with HNSqCCs who are found to harbor solitary lung nodules, but conventional diagnostic studies including light microscopy and immunohistochemistry are generally useless when both carcinomas are of the squamous type.(1,3) On clinical grounds, length of disease free progression represents an important distinguishing criterion. In most studies, 2-5 years is used as the threshold: a SqCC in the lung is regarded as a metastasis when detected within this time frame, and as a new primary when detected beyond this threshold. $(8,10,19,30)$ Evidence supporting this clinical criteria is largely empirical,(14) and doubts about the accuracy of these time honored practices have prompted novel strategies based on molecular genetic fingerprinting. Comparison of multiple tumors for patterns of microsatellite alterations, specific gene mutations and other molecular genetic parameters has been advocated as a better way to clarify the fundamental distinction between a second lung carcinoma and a lung metastasis. $(14,15,23,36)$ Widespread integration of these novel strategies into routine clinical practice, however, has not been forthcoming. Transfer into the clinical arena has been limited by cost, technical feasibility, and the inherent instability of the genetic profile of a tumor over time.

Oncogenic human papillomavirus (HPV), especially type 16, has been established as a causative agent in a subset of HNSqCCs.(16) HPV is detected in up to $82 \%$ of oropharyngeal carcinomas, (33) but is not commonly detected in $\mathrm{HNSqCCs}$ from nonoropharyngeal head and neck sites. This site selectivity has been exploited in efforts to establish the site of tumor origin for those patients with $\mathrm{HNSqCC}$ who develop metastases. As one important example, the detection of HPV in a cervical lymph node metastasis reliably points to the oropharynx as the site of tumor origin in those patients who present with a neck mass. $(4,5,42)$ Some have advocated HPV detection as a means to distinguish lung metastases from primary lung carcinoma, $(39,41)$ but this strategy is valid only to the degree that high risk HPV does not cause lung cancer. To date, the role of HPV in the development of primary lung carcinoma is unclear with detection rates ranging widely from $0 \%$ to $78 \%$.(35) The purpose of this study was two-fold: 1 ) determine the prevalence of high-risk HPV in primary lung cancers using an in-situ hybridization approach, and 2) employ HPV analysis as a means of clarifying tumor relationships in patients with HNSqCCs who develop a SqCC in their lungs.

\section{Materials and Methods}

Study approval was obtained from the Johns Hopkins Medical Institutions Internal Review Board. The pathology files of the Johns Hopkins Medical Institutions were reviewed for all patients with a squamous carcinoma of the head and neck (HNSqCC), biopsied or resected between 1985 and 2010, who also developed a squamous cell carcinoma (SqCC) in their lungs. All slides were reviewed, and a formalin-fixed and paraffin-embedded tissue block of the lung $\mathrm{SqCC}$ was selected for in situ hybridization and immunohistochemistry. For patients with primary oropharyngeal carcinomas, the corresponding $\mathrm{HNSqCC}$ was also analyzed. Medical records were reviewed to document tumor site, tumor stage and the time interval from treatment of the $\mathrm{HNSqCC}$ to diagnosis of the $\mathrm{SqCC}$ in the lung. 
The same pathology files were also reviewed to select 20 patients without a prior cancer who had undergone lung resections for primary squamous cell carcinoma of the lung showing prominent basaloid features. We specifically targeted basaloid SqCCs as the basaloid phenotype has been associated with HPV infection in the oropharynx and other sites (e.g. vulva, anus, penis).(6,11,13,21) To evaluate a broader spectrum of primary lung carcinomas, tissue microarrays were constructed from a variety of lung cancer types including 74 adenocarcinomas, 46 SqCCs, 12 non-small cell carcinomas (not otherwise specified), 11 large cell/pleomorphic carcinomas, and 3 small cell carcinomas. The tissue was obtained from routine formalin-fixed ( $10 \%$ buffered formalin), paraffin-embedded blocks, and three core samples were taken from each block to address tumor heterogeneity.

\section{Immunohistochemistry}

All of the carcinomas in the lung were evaluated by immunohistochemistry for expression of a biomarker of HPV E7 oncoprotein activity, the CDK-inhibitor p16. Five micron sections of formalin-fixed and paraffin-embedded tissues were deparaffinized and subjected to antigen retrieval using $10 \mathrm{mM}$ citrate buffer $\left(92^{\circ} \mathrm{C}\right.$ for 30 minutes). P16 expression was evaluated by use of a mouse monoclonal antibody against p16 (MTM Laboratories, Heidelberg, Germany) visualized using the Ultra view polymer detection kit (Ventana Medical Systems, Inc. Tucson, AZ) on a Ventana BenchmarkXT autostainer (Ventana). P16 expression was scored as positive if strong and diffuse nuclear and cytoplasmic staining was present in $\geq 70 \%$ of the tumor.(33)

\section{In situ hybridization}

Five-micron sections from the tissue microarrays and the formalin-fixed paraffin embedded tumor blocks were evaluated for the presence of HPV DNA by in situ hybridization. Two different detection assays were used. A type 16 specific assay was performed using the in situ hybridization catalyzed signal amplification method for biotinylated probes (DAKO GenPoint, Carpinteria, CA). Briefly, 5- $\mu \mathrm{m}$ tissue sections underwent deparaffinization, heatinduced target retrieval in citrate buffer, and digestion using Proteinase K (Roche Diagnostics, Indianapolis, IN). Slides were subsequently hybridized with a biotinylated HPV16 type-specific probe (DAKO, Carpintera, CA). Signal amplification was performed by consecutive application of streptavidin-HRP complex and biotinyl tyramide. Visualization of positive hybridization signals was performed by incubation with the chromogenic substrate diaminobenzidine. For broader high risk HPV detection, we also used the Ventana Inform HPV III Family 16 Probe (B) kit (Ventana Medical Systems, Tucson, AZ). For this assay the slides were conditioned using Ventana cell conditioner \#2 and ISHprotease 3. Hybridization was performed using the HPV III Family 16 probe set that captures HPV genotypes 16, 18, 33, 35, 45, 51, 52, 56 and 66. Signals were detected with the ISH iView Blue Plus Detection Kit, which is an indirect biotin-streptavidin system that detects fluorescein-labeled probes. The kit utilizes an alkaline phosphatase enzyme and NBT/BCIP substrate chromogen reaction that provides an intense blue, permanent color and a red counter stain. All reagents are provided pre-diluted and ready-to-use on BenchMark Series automated slide stainers (Ventana Medical Systems, Tucson, AZ). For both detection assays, punctate hybridization signals localized to the tumor cell nuclei defined an HPV-positive tumor. The HPV studies were reviewed by three surgical pathologists with experience interpreting in situ hybridization (J.A.B., P.B.I., and W.H.W). HPV16-positive controls included an HPV16-positive oropharyngeal cancer and the SiHa and CaSki cell lines. The $\mathrm{SiHa}$ cell line is known to harbor 1 to 2 copies of integrated HPV-16 per cell, and the CaSki cell line is known to harbor 60 to 600 copies of integrated HPV-16 per cell. 


\section{HPV E6 sequencing}

DNA was extracted from 5 slides of 5- $\mu \mathrm{m}$ thick formalin-fixed paraffin embedded tumor samples. Briefly, tissues were deparaffinizated using Xylene and scraped off the slides, followed by digestion with $50 \mu \mathrm{g} / \mathrm{mL}$ proteinase $\mathrm{K}$ (Boehringer Mannheim) in the presence of $1 \% \mathrm{SDS}$ at $48^{\circ} \mathrm{C}$ for 2 days. DNA was then extracted using UltraPure ${ }^{\mathrm{TM}}$ Phenol:Chloroform:Isoamyl Alcohol reagents (invitrogen, Carlsbad, CA) following the manufacturer's instructions. Full-length E6 was amplified using a PCR reaction, purified and sequenced with both forward and reverse primers. Sequencing data was then aligned to compare the E6 sequence to the previously described 23 HPV E6 variants.(40)

\section{Results}

The results of HPV analysis are summarized in Table 1 and Figure 1. A total of sixty-eight patients were identified who had a primary $\mathrm{HNSqCC}$ and went on to develop a SqCC in their lungs. We were able to obtain tissue blocks on fifty-four cases, which were included in the study. Two patients had two primary HNSqCCs. In 32 cases, the lung carcinoma presented as a solitary mass, while in 21 cases there were multiple $(>2)$ lung nodules; in 1 case, radiographic information was not available. There were a total of 166 primary lung SqCCs from patients without a prior HNSqCC. Overall, high-risk HPV was detected by in situ hybridization in 11 of the $220(5 \%)$ carcinomas involving the lung. HPV was not detected in any of the 166 primary lung carcinomas from patients without a prior HNSqCC, but it was detected in 11 of $54(20 \%)$ lung SqCCs from patients with a prior HNSqCC. In these patients, HPV was detected in 11 of 28 patients with an oropharyngeal primary, but in none of the 26 patients with $\mathrm{HNSqCC}$ arising only from a non-oropharyngeal site (39\% vs. $0 \%, \mathrm{p}=0.0003$, Fisher exact, 2-sided). In 7 cases (64\%), the HPV-positive lung cancer presented as a solitary mass, while the remaining four cases presented with multiple nodules. All $11 \mathrm{HPV}$-positive tumors demonstrated prominent basaloid features including a lobular pattern of growth, nuclear hyperchromasia, a high nuclear to cytoplasmic ratio, and absent to minimal keratinization.

The HPV status and histopathologic features of the tumor pairs were compared for those patients with oropharyngeal SqCC who developed a SqCC in their lung. Tissue blocks were available for 22 of the 28 oropharyngeal carcinomas. HPV status was concordant in 21 (95\%) cases. In 10 cases the tumor pairs were HPV positive; and in 11 cases the tumor pairs were HPV negative. In these concordant HPV-positive cases, the basaloid phenotype was well developed in both the oropharyngeal carcinomas and the paired lung carcinomas (Figure 2). The single discordant case involved a patient with an HPV positive oropharyngeal $\mathrm{SqCC}$ who developed an HPV negative $\mathrm{SqCC}$ in the lung 14 months after treatment of the primary tumor. In the HPV positive concordant cases, the time intervals from treatment of the oropharyngeal primary to detection of carcinoma in the lung were 1,8 , $11,14,15,31,32,53,96$ and 97 months (range 1 to 97 months, mean 36 months, median 23 months).

Notably, 2 HPV-positive carcinomas were detected in the lung 8 years after treatment of the oropharyngeal primary. To address whether these tumor pairs were clonally related, we sequenced E6 to determine whether the specific HPV-16 variant in the oropharynx and lung was the same or different. For one of the patients, E6 sequencing confirmed that the tumor pair harbored the identical 131/2GG HPV-16 variant.(40) E6 sequencing could not be performed in the other tumor pair due to insufficient tissue in the lung biopsy.

P16 overexpression as visualized by immunohistochemical staining is commonly used as a surrogate marker for the presence of high risk HPV. Overall, p16 overexpression was observed in 54 of $220(24.5 \%)$ carcinomas involving the lung. In contrast to HPV detection 
by in situ hybridization, p16 overexpression in carcinomas involving the lung was not restricted to patients with prior oropharyngeal HNSqCCs. P16 overexpression was detected in 37 of $166(22 \%)$ lung carcinomas from patients without any prior HNSqCC including 3 of $3(100 \%)$ small cell carcinomas, 4 of $11(25 \%)$ large cell/pleomorphic carcinomas, 15 of 74 (20\%) adenocarcinomas, 14 of 66 (21\%) squamous cell carcinomas, and 1 of $12(8 \%)$ nonsmall cell carcinomas not otherwise specified. Among the squamous cell carcinomas, strong p16 staining was present in 8 of $20(40 \%)$ tumors demonstrating the basaloid phenotype. For patients with a prior $\mathrm{HNSqCC}, \mathrm{p} 16$ overexpression in the lung carcinoma was more common in patients with prior oropharyngeal carcinomas than those without oropharyngeal carcinomas ( $54 \%$ vs. $8 \%, \mathrm{p}=0.0003$, Fisher exact, 2 -sided).

\section{Discussion}

In patients with head and neck squamous cell carcinoma (HNSqCC), a squamous cell carcinoma $(\mathrm{SqCC})$ in the lung represents either another primary tumor or a metastasis. This distinction greatly influences patient prognosis and could guide treatment strategies, but the nature of the lung nodule is often difficult to discern using standard clinical and histologic parameters. Some have advocated comparative analysis of various genetic parameters such as gene mutations or microsatellite alterations; $(14,15,23,36)$ but implementation has been constrained by cost, technical considerations, and the inherent instability of a tumor's genetic profile over time. HPV analysis is an attractive alternative given that HPV is an established causative agent for a subset of HNSqCCs, the incidence of these HPV-related HNSqCCs is rising to the point that they now dominate the head and neck oncology landscape, and HPV tumor analysis is relatively straightforward using widely available insitu and immunohistochemical techniques. The feasibility of this approach was demonstrated in a study by Weichert et al where concordant HPV positivity was taken as evidence of metastatic spread for patients with primary SqCCs of the cervix or head and neck who developed SqCCs in their lungs.(39) Using an expanded number of cases, we confirm that the presence of high risk HPV in lung carcinomas is entirely restricted to patients with HPV-related SqCC of the oropharynx, and its detection reliably discriminates lung metastases from primary lung cancers in patients with HPV-related HNSCC. HPV analysis may be particularly valuable in those situations where the relationship between the tumor in the oropharynx and lung is clouded by the clinical and/or radiographic picture, as when an HPV-positive metastasiss presents as a solitary lung nodule (as in 64\% of our cases) or when the lung metastasis is discovered many years after treatment of the HPVpositive oropharyngeal cancer.

Our inability to detect HPV in primary lung carcinomas not only strengthens the use of HPV testing as a discriminatory diagnostic tool, but helps address a fundamental question regarding lung cancer causation. Persistent uncertainty regarding the role of high risk HPV in lung cancer development largely reflects widely disparate detection rates ranging from $0 \%$ to $78 \%$.(35) Studies demonstrating a high prevalence of HPV in primary lung cancers have primarily used non-quantitative PCR-based assays that are unable to distinguish infections that are biologically relevant from those that are not.(7,9,20,24,38,43) Unlike these PCR-based detection methods, in situ hybridization permits direct visualization of viral tissue distribution. The assay used in this study has single viral-copy sensitivity and is strongly correlated with HPV E6 and E7 oncogene expression - the gold standard for defining a tumor as HPV-associated.(32,34) In effect, a pattern of hybridization signals localized to the nuclei of a clonally expanded population of neoplastic cells supports a viral role that is causal rather than incidental. Results based on in situ hybridization suggest that PCR-based analysis may vastly overestimate the frequency and relevance of HPV in primary lung cancers. Lim et al were unable to detect any HPV-positivity among 110 primary lung adenocarcinomas,(26) and we did not detect HPV among a broader range of 
primary lung carcinomas types including SqCCs with the basaloid phenotype - a phenotype that is commonly associated with HPV infection in non-pulmonary sites including the oropharynx, vulva, penis and anus. $(6,11,13,21)$

Overexpression of $\mathrm{p} 16$ is observed when $\mathrm{pRb}$ is inactivated by the E7 oncoprotein of oncogenic HPV types.(18) By contrast, p16 expression is not detectable in HPV-negative HNSqCCs due to (epi)genetic silencing.(28) Accordingly, p16 overexpression as detected by immunohistochemical staining is now widely accepted as a surrogate marker for the presence of high risk HPV in oropharyngeal SqCCs. In the lung, the Rb gene may be inactivated by mechanisms other than E7 oncoprotein expression,(29) yet still resulting in high levels of p16 expression. Consequently, high levels of p16 proteins levels may be encountered in lung carcinomas that are entirely unrelated to high risk HPV.(17,31) In this study, for example, $22 \%$ of all primary lung carcinomas and $21 \%$ of primary lung SqCC were p16 positive in the absence of high risk HPV. P16 expression in a significant proportion of primary lung carcinomas cautions against the use of p16 immunohistochemical staining as a surrogate marker of HPV infection when dealing with carcinomas that involve the lungs.

Although up to $80 \%$ of oropharyngeal carcinomas are HPV positive, most of the SqCCs that arose in the lungs of patients with oropharyngeal carcinomas were HPV negative. This observation is not altogether unexpected. First, HPV-positive HNSqCCs demonstrate higher intrinsic sensitivity to radiation therapy and chemotherapy. $(2,12)$ The differential response to chemotherapy observed locally and regionally could also explain the disproportionally low frequency of HPV positive oropharyngeal carcinomas at distant sites. Second, HPV positivity is associated with lower exposure to tobacco and, in turn, a lower association with smoking-related second primary tumors. $(2,25)$ Some of the lung SqCCs in the lungs of patients with HPV negative oropharyngeal carcinomas may represent smoking related second primary tumors.

HPV detection as a means to track disease progression helps disclose patterns of true clinical behavior in ways that may challenge long held notions based on empirical findings. As one example, a long time interval from treatment of the head and neck carcinoma to detection the carcinoma in the lung has been intuitively taken as evidence of a second independent lung primary. $(8,10,19,30)$ Based on concordant HPV positivity, we identified 2 patients who developed lung metastases 8 years after treatment of their oropharyngeal primaries, well beyond the 2-5 year interval that is usually set as the threshold for distinguishing primary from metastatic $\mathrm{SqCC}$ of the lung. The coincidental development of two independent primary HPV-related squamous cell carcinomas is highly improbable as we were unable to detect HPV in lung cancers arising in patients without oropharyngeal primaries including those squamous cell carcinomas of the lung with prominent basaloid features. Moreover, HPV E6 sequence analysis of one of the oropharyngeal/lung cancer pairs revealed the same variant of HPV type 16, further supporting a lung metastasis despite an 8 year interval. HPV positivity is recognized as a powerful prognostic factor signaling improved survival for patients with HNSqCC, $(2,12)$ but the potential for these virus-related tumors to metastasize long after curative therapy argues for extended patient follow-up.

\section{Acknowledgments}

This work was funded by the National Institute of Dental and Craniofacial Research (P50 DE019032-06) 


\section{References}

1. Adkins PC, Wesselhoeft CW Jr, Newman W, et al. Thoracotomy on the patient with previous malignancy: metastasis or new primary? J Thorac Cardiovasc Surg. 1968; 56:351-361. [PubMed: 5677690]

2. Ang KK, Harris J, Wheeler R, et al. Human papillomavirus and survival of patients with oropharyngeal cancer. N Engl J Med. 2010; 363:24-35. [PubMed: 20530316]

3. Askin FB. Something old? Something new? Second primary or pulmonary metastasis in the patient with known extrathoracic carcinoma. Am J Clin Pathol. 1993; 100:4-5. [PubMed: 8346735]

4. Begum S, Gillison ML, Ansari-Lari MA, et al. Detection of human papillomavirus in cervical lymph nodes: a highly effective strategy for localizing site of tumor origin. Clin Cancer Res. 2003; 9:6469-6475. [PubMed: 14695150]

5. Begum S, Gillison ML, Nicol TL, et al. Detection of human papillomavirus-16 in fine-needle aspirates to determine tumor origin in patients with metastatic squamous cell carcinoma of the head and neck. Clin Cancer Res. 2007; 13:1186-1191. [PubMed: 17317828]

6. Begum S, Westra WH. Basaloid squamous cell carcinoma of the head and neck is a mixed variant that can be further resolved by HPV status. Am J Surg Pathol. 2008; 32:1044-1050. [PubMed: 18496144]

7. Bohlmeyer T, Le TN, Shroyer AL, et al. Detection of human papillomavirus in squamous cell carcinomas of the lung by polymerase chain reaction. Am J Respir Cell Mol Biol. 1998; 18:265269. [PubMed: 9476914]

8. Buwalda J, Zuur CL, Lubsen H, et al. Annual chest X-ray in patients after treatment for laryngeal or oral cancer: only a limited number of second primary lung cancers detected. Ned Tijdschr Geneeskd. 1999; 143:1517-1522. [PubMed: 10443275]

9. Castillo A, Aguayo F, Koriyama C, et al. Human papillomavirus in lung carcinomas among three Latin American countries. Oncol Rep. 2006; 15:883-888. [PubMed: 16525675]

10. Chung KY, Mukhopadhyay T, Kim J, et al. Discordant p53 gene mutations in primary head and neck cancers and corresponding second primary cancers of the upper aerodigestive tract. Cancer Res. 1993; 53:1676-1683. [PubMed: 8453641]

11. Cubilla AL, Lloveras B, Alejo M, et al. The basaloid cell is the best tissue marker for human papillomavirus in invasive penile squamous cell carcinoma: a study of 202 cases from Paraguay. Am J Surg Pathol. 2010; 34:104-114. [PubMed: 20035150]

12. Fakhry C, Westra WH, Li S, et al. Improved survival of patients with human papillomaviruspositive head and neck squamous cell carcinoma in a prospective clinical trial. J Natl Cancer Inst. 2008; 100:261-269. [PubMed: 18270337]

13. Frisch M. On the etiology of anal squamous carcinoma. Dan Med Bull. 2002; 49:194-209. [PubMed: 12238281]

14. Geurts TW, Nederlof PM, van den Brekel MW, et al. Pulmonary squamous cell carcinoma following head and neck squamous cell carcinoma: metastasis or second primary? Clin Cancer Res. 2005; 11:6608-6614. [PubMed: 16166439]

15. Geurts TW, van Velthuysen ML, Broekman F, et al. Differential diagnosis of pulmonary carcinoma following head and neck cancer by genetic analysis. Clin Cancer Res. 2009; 15:980985. [PubMed: 19188169]

16. Gillison ML, Koch WM, Capone RB, et al. Evidence for a causal association between human papillomavirus and a subset of head and neck cancers. J Natl Cancer Inst. 2000; 92:709-720. [PubMed: 10793107]

17. Gorgoulis VG, Zacharatos P, Kotsinas A, et al. Alterations of the p16-pRb pathway and the chromosome locus 9p21-22 in non-small-cell lung carcinomas: relationship with p53 and MDM2 protein expression. Am J Pathol. 1998; 153:1749-1765. [PubMed: 9846966]

18. Helbig M, Andl T, Kahn T, et al. The role of oncogenic human papillomaviruses in tonsillar squamous cell carcinomas with functional inactivation of the retinoblastoma protein. HNO. 1999; 47:796-803. [PubMed: 10525608] 
19. Hong WK, Lippman SM, Itri LM, et al. Prevention of second primary tumors with isotretinoin in squamous-cell carcinoma of the head and neck. N Engl J Med. 1990; 323:795-801. [PubMed: 2202902]

20. Kinoshita I, Dosaka-Akita H, Shindoh M, et al. Human papillomavirus type 18 DNA and E6-E7 mRNA are detected in squamous cell carcinoma and adenocarcinoma of the lung. Br J Cancer. 1995; 71:344-349. [PubMed: 7841051]

21. Kurman RJ, Toki T, Schiffman MH. Basaloid and warty carcinomas of the vulva. Distinctive types of squamous cell carcinoma frequently associated with human papillomaviruses. Am J Surg Pathol. 1993; 17:133-145. [PubMed: 8380681]

22. Leon X, Quer M, Diez S, et al. Second neoplasm in patients with head and neck cancer. Head Neck. 1999; 21:204-210. [PubMed: 10208662]

23. Leong PP, Rezai B, Koch WM, et al. Distinguishing second primary tumors from lung metastases in patients with head and neck squamous cell carcinoma. J Natl Cancer Inst. 1998; 90:972-977. [PubMed: 9665144]

24. Li Q, Hu K, Pan X, et al. Detection of human papillomavirus types 16, 18 DNA related sequences in bronchogenic carcinoma by polymerase chain reaction. Chin Med J (Engl). 1995; 108:610-614. [PubMed: 7587494]

25. Licitra L, Perrone F, Bossi P, et al. High-risk human papillomavirus affects prognosis in patients with surgically treated oropharyngeal squamous cell carcinoma. J Clin Oncol. 2006; 24:56305636. [PubMed: 17179101]

26. Lim WT, Chuah KL, Leong SS, et al. Assessment of human papillomavirus and Epstein-Barr virus in lung adenocarcinoma. Oncol Rep. 2009; 21:971-975. [PubMed: 19287995]

27. Rafferty MA, O’Dwyer TP. Secondary primary malignancies in head and neck squamous cell carcinoma. J Laryngol Otol. 2001; 115:988-991. [PubMed: 11779329]

28. Reed AL, Califano J, Cairns P, et al. High frequency of p16 (CDKN2/MTS-1/INK4A) inactivation in head and neck squamous cell carcinoma. Cancer Res. 1996; 56:3630-3633. [PubMed: 8705996]

29. Reissmann PT, Koga H, Takahashi R, et al. The Lung Cancer Study Group. Inactivation of the retinoblastoma susceptibility gene in non-small-cell lung cancer. Oncogene. 1993; 8:1913-1919. [PubMed: 8390038]

30. Rott T, Luzar B, Sorli J. Bronchopulmonary changes after laryngeal cancer treatment-differentiation between metastatic laryngeal and second primary cancer. Acta Otolaryngol Suppl. 1997; 527:167-169. [PubMed: 9197512]

31. Shapiro GI, Edwards CD, Kobzik L, et al. Reciprocal Rb inactivation and p16INK4 expression in primary lung cancers and cell lines. Cancer Res. 1995; 55:505-509. [PubMed: 7834618]

32. Shi W, Kato H, Perez-Ordonez B, et al. Comparative prognostic value of HPV16 E6 mRNA compared with in situ hybridization for human oropharyngeal squamous carcinoma. J Clin Oncol. 2009; 27:6213-6221. [PubMed: 19884544]

33. Singhi AD, Westra WH. Comparison of human papillomavirus in situ hybridization and p16 immunohistochemistry in the detection of human papillomavirus-associated head and neck cancer based on a prospective clinical experience. Cancer. 2010; 116:2166-2173. [PubMed: 20186832]

34. Smeets SJ, Hesselink AT, Speel EJ, et al. A novel algorithm for reliable detection of human papillomavirus in paraffin embedded head and neck cancer specimen. Int J Cancer. 2007; 121:2465-2472. [PubMed: 17680565]

35. Srinivasan M, Taioli E, Ragin CC. Human papillomavirus type 16 and 18 in primary lung cancers-a meta-analysis. Carcinogenesis. 2009; 30:1722-1728. [PubMed: 19620233]

36. Talbot SG, Estilo C, Maghami E, et al. Gene expression profiling allows distinction between primary and metastatic squamous cell carcinomas in the lung. Cancer Res. 2005; 65:3063-3071. [PubMed: 15833835]

37. Tepperman BS, Fitzpatrick PJ. Second respiratory and upper digestive tract cancers after oral cancer. Lancet. 1981; 2:547-549. [PubMed: 6116001]

38. Thomas P, De Lamballerie X, Garbe L, et al. Detection of human papillomavirus DNA in primary lung carcinoma by nested polymerase chain reaction. Cell Mol Biol (Noisy-le-grand). 1995; 41:1093-1097. [PubMed: 8747090] 
39. Weichert W, Schewe C, Denkert C, et al. Molecular HPV typing as a diagnostic tool to discriminate primary from metastatic squamous cell carcinoma of the lung. Am J Surg Pathol. 2009; 33:513-520. [PubMed: 19145203]

40. Wheeler CM, Yamada T, Hildesheim A, et al. Human papillomavirus type 16 sequence variants: identification by E6 and L1 lineage-specific hybridization. J Clin Microbiol. 1997; 35:11-19. [PubMed: 8968874]

41. Zannoni GF, Sioletic S, Fadda G, et al. The role of HPV detection and typing in diagnosis of pulmonary metastatic squamous cell carcinoma of the uterine cervix. Histopathology. 2008; 53:604-606. [PubMed: 18983472]

42. Zhang MQ, El-Mofty SK, Davila RM. Detection of human papillomavirus-related squamous cell carcinoma cytologically and by in situ hybridization in fine-needle aspiration biopsies of cervical metastasis: a tool for identifying the site of an occult head and neck primary. Cancer. 2008; 114:118-123. [PubMed: 18300234]

43. Zhang X, Zhu Y, Li L. Point mutation of p53 and detection of human papillomavirus DNA in bronchogenic carcinoma. Zhonghua Nei Ke Za Zhi. 1995; 34:673-675. [PubMed: 8731828] 


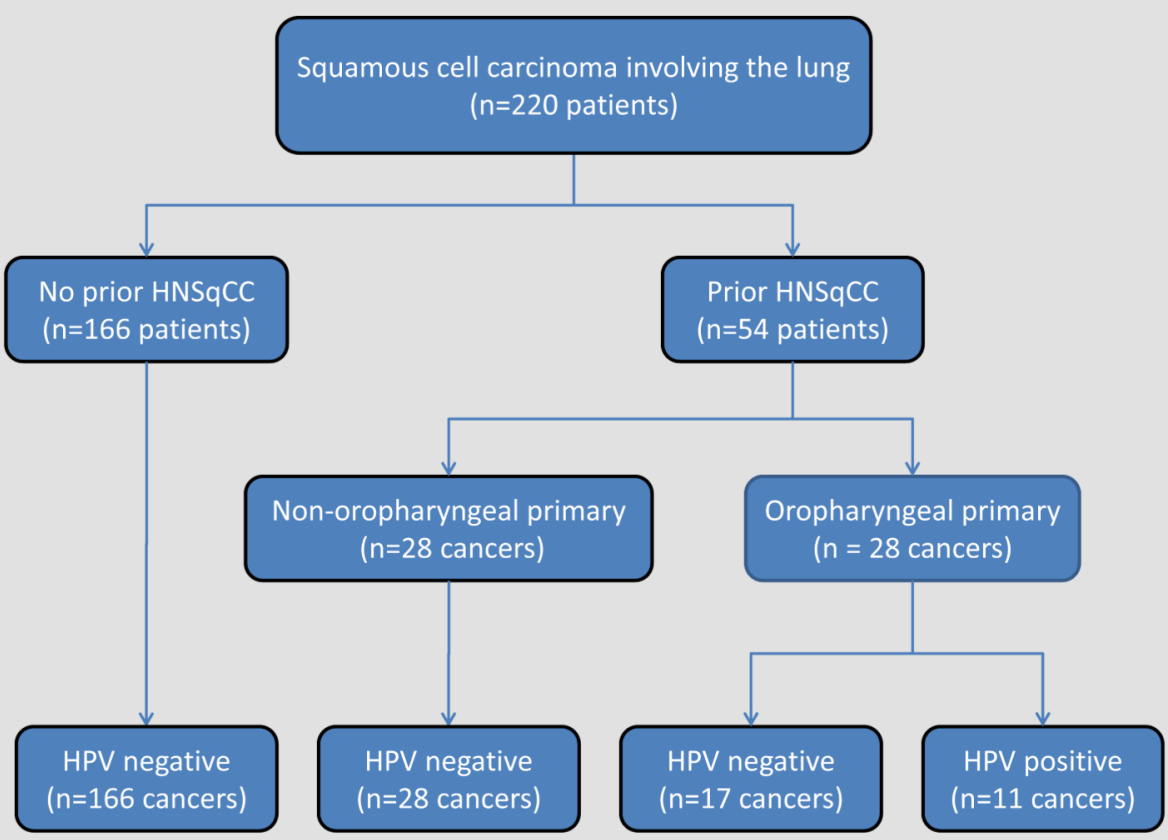

Figure 1.

HPV detection in carcinomas involving the lungs of patients with and without prior squamous cell carcinomas of the head and neck. HPV detection is strictly limited to those patients with a prior squamous cell carcinoma arising from the oropharynx. 


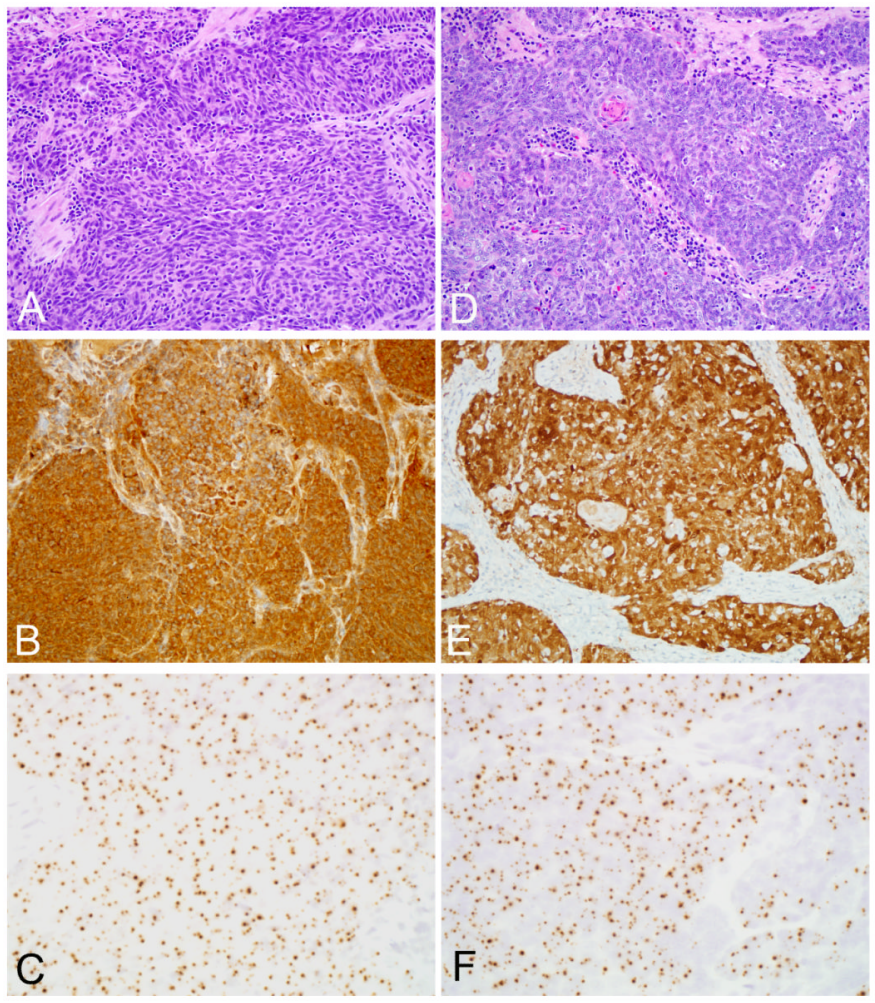

Figure 2.

Squamous cell carcinomas of the base of tongue (A-C) and lung (D-F) from the same patient. The carcinomas are morphologically very similar ( $\mathrm{A}$ and $\mathrm{D}$, routine hematoxylin and eosin staining), and they exhibit concordant patterns of p16 expression (B and E, p16 immunohistochemistry) and HPV in situ hybridization (C and F, HPV-16 in situ hybridization). 
Table 1

P16 expression and HPV status of lung carcinomas including squamous cell carcinomas in patients with prior squamous cell carcinomas of the head and neck

\begin{tabular}{|lcc|}
\hline Tumor type & P16 IHC (\%) & HPV ISH (\%) \\
Small cell carcinoma & $3 / 3(100)$ & $0 / 3(0)$ \\
Non-small cell carcinoma, NOS & $1 / 12(8)$ & $0 / 12(0)$ \\
Adenocarcinoma & $15 / 74(20)$ & $0 / 74(0)$ \\
Large cell/pleomorphic carcinoma & $4 / 11(36)$ & $0 / 11(0)$ \\
Squamous cell carcinoma & & \\
$\quad$ No prior squamous cell carcinoma & $14 / 66(21)$ & $0 / 66(0)$ \\
Prior head and neck squamous cell carcinoma* & $17 / 54(31)$ & $11 / 54(20)$ \\
$\quad$ & $15 / 28(54)$ & $11 / 28(39)$ \\
$\quad$ oropharynx & $1 / 7(14)$ & $0 / 7(0)$ \\
larynx cavity & $1 / 20(5)$ & $0 / 20(0)$ \\
$\quad$ hypopharynx & $0 / 1(0)$ & $0 / 1(0)$ \\
\hline
\end{tabular}

IHC, immunohistochemistry; HPV, human papillomavirus; ISH, in situ hybridization; NOS, not otherwise specified

* two patients had primary SqCCs involving the oropharynx and a non-oropharyngeal site 